\title{
Identificação de sinais de Transtornos do Desenvolvimento da Coordenação em crianças de três a seis anos e possibilidades de atuação da Terapia Ocupacional*
}

\section{Identify signs of developmental coordination disorders in children aged three to six years with and possible performance of Occupational Therapy}

\author{
Érika Papa Mazer'1, Patrícia Carla de Souza Della Barba ${ }^{2}$
}

\begin{abstract}
MAZER, E. P.; DELLA BARBA P. C. S. Identificação de sinais de Transtornos do Desenvolvimento da Coordenação em crianças de três a seis anos e possibilidades de atuação da Terapia Ocupacional. Rev. Ter. Ocup. Univ. São Paulo, v. 21, n. 1, p. 74-82, jan./abr. 2010.

RESUMO: O Transtorno do Desenvolvimento da Coordenação - TDC - tem sido estudado como um atraso no desenvolvimento motor, no qual as dificuldades motoras podem aparecer sem relação com distúrbios neurológicos ou traumas. Manifesta-se precocemente e as crianças podem apresentar, ainda na pré-escola, atraso nas aquisições motoras. Independente da causa, a prevenção e a detecção do TDC exigem avaliação criteriosa e uso de testes específicos para diagnosticá-lo. Objetivos: elencar os principais aspectos do Transtorno do Desenvolvimento da Coordenação e detectar os sinais em crianças já identificadas com risco para atraso de desenvolvimento em creches e pré-escolas. Procedimento Metodológico: foi elaborado e aplicado um protocolo de avaliação de sinais do transtorno para a faixa etária de três a seis anos. Abordagem Teórica: O protocolo é composto por duas partes, sendo a primeira em forma de questionário aos educadores e a segunda uma avaliação do desenvolvimento da criança. Resultados: O estudo foi realizado com 10 crianças, sendo três identificadas com sinais do transtorno. Os resultados apontam tanto para a possibilidade de identificação do transtorno, como para a necessidade de se aprimorar o instrumento para que possa ser replicado. Conclusões: São enfatizadas também as possibilidades de atuação da Terapia Ocupacional junto a esta população, pela possibilidade do olhar para seu cotidiano e sua inserção nos diversos contextos da criança.
\end{abstract}

DESCRITORES: Transtornos das habilidades motoras. Transtorno do Desenvolvimento da coordenação. Terapia Ocupacional. Protocolos. Avaliação. Pré-escolar. Atividades cotidianas.

\footnotetext{
* Este trabalho é parte integrante do projeto de pesquisa intitulado Transtornos do Desenvolvimento da Coordenação em crianças: a prematuridade como fator de risco e as possibilidades de intervenção da Terapia Ocupacional, vinculado ao PROGRAMA INTEGRADO DE APOIO AO DOCENTE RECÉM-DOUTOR - PIADRD-PROPQ-UFSCar.

1. Aluna do curso de graduação de Terapia Ocupacional da Universidade Federal de São Carlos, bolsista de iniciação científica.

2. Terapeuta Ocupacional, doutora em Educação Especial, professora adjunta do Departamento de Terapia Ocupacional da Universidade Federal de São Carlos.

Endereço para correspondência: Departamento de Terapia Ocupacional. Rodovia Washington Luís, km 235, São Carlos, SP. CEP: 13565905. Email: erikapapamazer@yahoo.com.br, patriciabarba@ufscar.br
} 


\section{INTRODUÇÃO}

aquisição de habilidades motoras básicas
apresenta geralmente uma seqüência de
desenvolvimento previsível. No entanto, em algumas situações e por fatores diversos (orgânicos e ambientais), pode ocorrer atraso nessas aquisições. Dificuldades motoras são muitas vezes descritas como concomitantes a desordens cognitivas ou neurológicas. Mas, existem condições em que as dificuldades motoras podem manifestar-se de maneira isolada, ou seja, não têm relação com distúrbios neurológicos ou traumas. Para crianças com problemas de coordenação motora, tarefas simples como vestir uma camiseta, colocar comida no prato ou segurar um lápis para escrever são desafios constantes.

Desde o século passado, têm sido utilizadas variadas terminologias para identificar os transtornos de coordenação motora. O termo "coordenação muscular pobre" já era usado em 1926, e o termo "dispraxia do desenvolvimento" era utilizado em 1937 para se referir às crianças que apresentavam falhas no desenvolvimento das habilidades motoras. Os termos "apraxia", "agnosia", "criança desajeitada", "síndrome psicomotora" também foram utilizados ao longo dos anos (MAGALHÃES, 2007).

Tal variedade de terminologias tem gerado confusão e também inconsistência na identificação dos sintomas e conseqüentemente, no tratamento das crianças que apresentam o quadro. Diante disso, no Fórum de Consenso realizado no Canadá em 1994, pesquisadores decidiram recomendar como nomenclatura universal na clínica e na pesquisa o termo Transtornos do Desenvolvimento da Coordenação - TDC (ou em inglês, Developmental Coordination Disorder - $D C D$ ) para referir-se a déficits motores globais na criança. A partir desta data, a maioria dos trabalhos publicados usa esta terminologia (MAGALHÃES, 2007).

De acordo com o DSM-IV - (classificação 315.4), o termo Transtornos do Desenvolvimento da Coordenação se aplica aos casos "em que, na ausência de outros distúrbios fisicos/neurológicos conhecidos, existe prejuizo acentuado do desenvolvimento da coordenação motora, com desempenho significativamente abaixo do esperado para a idade cronológica e nível cognitivo da criança, nas atividades diárias (AVD) que requerem coordenação motora" (MAGALHÃES, 2007, p. 315; DAVID, 1995; MARTINI; POLATAJKO, 1998).

No manual DSM-IV (Associação Psiquiátrica Americana, 2002), o TDC é caracterizado por um comprometimento no desempenho de atividades diárias e no rendimento escolar tendo por base a idade cronológica e a inteligência medida da criança, onde o comprometimento não se deve a uma condição médica geral. Já na publicação CID-10 (OMS, 1993), o TDC é denominado de transtorno específico do desenvolvimento da função motora onde sua principal característica é o sério prejuízo da coordenação motora.

Os sinais geralmente associados ao TDC são desajeitamento e inconsistência no desempenho de tarefas, coordenação motora pobre, problemas de ritmo e de transferência de aprendizagem, declínio do desempenho com a repetição, tensão corporal e excesso de atividade muscular na execução de tarefas motoras (SELLER, 1995). A criança pode demonstrar dificuldade nas tarefas de autocuidado, como vestir-se e usar utensílios, nas atividades acadêmicas, como a escrita e o traçado, e nas atividades de lazer, com pobre desempenho em esportes, no uso de equipamentos de parques e brinquedos infantis, além de dificuldades nas interações sociais. Os autores ressaltam a importância da intervenção ser voltada a superar as desvantagens derivadas das incapacidades (MARTINI; POLATAJKO, 1998; DANTAS; MANOEL, 2009).

Embora a dificuldade motora seja aparente, alguns autores relatam que as características associadas ao TDC não atingem somente a maioria das habilidades motoras notáveis, mas apresentam associações com os aspectos emocionais e sociais (WRIGHT; SUGDEN, 1996).

De acordo com as evidências, as características específicas do transtorno estão vinculadas a um comportamento descoordenado e impreciso, verificado principalmente nas tarefas motoras que requerem maior grau de coordenação e interação entre os segmentos corporais. Em vista dessas dificuldades, percebe-se a necessidade de intervenção no processo de ensino-aprendizagem o mais precoce possível a fim de evitar problemas futuros como dificuldades escolares e baixa auto-estima devido à exclusão que essas crianças possam sofrer.

O aspecto mais perverso do transtorno é o de que a ausência de sinais neurológicos clássicos leva a uma atitude de incredulidade diante do problema, negligenciando-se a sua existência. Outro aspecto delicado é a crença de que as crianças naturalmente irão recuperar-se do estado de dificuldade motora.

Segundo Lacerda et al. (2007), os critérios para o diagnóstico dos transtornos do desenvolvimento da coordenação ainda são inconsistentes, o que dificulta a intervenção adequada. Vários testes motores têm sido utilizados para a identificação do TDC, mas tem aplicação restrita no Brasil, devido a ausência de normas para a criança brasileira, como o Movimento ABC - MABC (HENDERSON; SUDGEN, 1992), o teste de Gubbay 
(GUBBAY, 1975), o Bruininks Ozeretsky Teste de Proficiência Motora - BOTMP (BRUININKS, 1978).

Uma revisão da literatura na área encontrou alguns trabalhos enfatizando exames e avaliações voltadas à identificação de transtornos motores em crianças, como: DIAMENT (que em 1982 mostrou a padronização do desenvolvimento neurológico da criança normal e os critérios para o exame de crianças normais); SOUZA et al (2007), que investigou o teste $\mathrm{ABC}$ do movimento, especificamente a bateria de testes motores, em crianças de ambientes diferentes;.o trabalho de MISSIUNA (2006) apontando a importância do Terapeuta Ocupacional reconhecer os aspectos do TDC e assim, auxiliar no diagnóstico. Destacase estudo de MAGALHÃES (2004), que descreveu as etapas iniciais da Avaliação da Coordenação e Destreza Motora (ACOORDEM), um teste brasileiro em fase de validação para a detecção do TDC em crianças de 4 a 8 anos de idade e o trabalho de LACERDA (2007) que teve como objetivo principal examinar a validade de conteúdo dos Questionários de Pais e Professores da ACOORDEM.

Diante da constatação de que o Transtorno do Desenvolvimento da Coordenação pode causar comprometimentos ao desempenho motor, escolar, emocional e social da criança, a Terapia Ocupacional tem muito a contribuir, pois são profissionais capacitados para analisar o desenvolvimento das habilidades motoras e das atividades da vida diária.

O Terapeuta Ocupacional pode auxiliar os pais, os professores e a criança a desenvolverem uma melhor compreensão das dificuldades de coordenação que a criança está enfrentando. Pode ser necessário ensinar-lhe estratégias para compensar seus problemas motores, assim como oferecer à criança oportunidades adequadas para praticar e aprender habilidades motoras e se conscientizar tanto de seus pontos fortes como de suas limitações, para que possa lidar com suas dificuldades.

Neste contexto, o presente estudo teve como objetivo detectar sinais de Transtorno do Desenvolvimento da Coordenação em crianças já identificadas com risco para atraso de desenvolvimento em creches e pré-escolas municipais de uma cidade do interior do estado de São Paulo. Para tanto, foi elaborado e aplicado um protocolo de avaliação de sinais do transtorno para a faixa etária de três a seis anos.

Pretende-se, adicionalmente, apontar as possibilidades de atuação da Terapia Ocupacional junto a esta população, partindo do pressuposto de que a correta avaliação do transtorno possibilita a intervenção adequada.

Este trabalho faz parte do projeto de pesquisa denominado Transtornos do Desenvolvimento da Coordenação em crianças: a prematuridade como fator de risco e as possibilidades de intervenção da Terapia Ocupacional, vinculado ao Programa Integrado de Apoio ao Docente Recém-doutor - PIADRD-PROPQ-UFSCar. A pesquisa foi desenvolvida entre 2008-2010 e foi aprovada pelo Comitê de Ética da UFSCar sob número nº 032/2008.

\section{PROCEDIMENTOS METODOLÓGICOS}

O presente estudo teve origem em um rastreamento de crianças com histórico de prematuridade iniciado por Martinez e col. (2007), que localizou e identificou crianças com risco para atraso do desenvolvimento em creches e pré-escolas de uma cidade do interior de São Paulo. $\mathrm{O}$ rastreamento das crianças foi baseado na seleção dos critérios de nota da PEDI (Pedriatric Evaluation of Disability Inventory), descrita por Mancini (2005) e da EPP-DP (Escala de Percepção dos Professores sobre o Desempenho e Participação), apresentada por Martinez e col. (2007) e apontou 88 crianças com possíveis comprometimentos, sendo que 43 foram encaminhadas para o projeto de pesquisa "Transtornos do Desenvolvimento da Coordenação em crianças: a prematuridade como fator de risco e as possibilidades de intervenção da Terapia Ocupacional" e 15 foram selecionadas com hipótese de TDC. Essa seleção foi baseada na associação entre os critérios de avaliação do Transtorno do Desenvolvimento da Coordenação segundo o DSM - IV e o CID-10 e os baixos escores dessas crianças na PEDI e na EPP-DP.

Tendo em mãos a autorização para avaliar as crianças no ambiente das creches e pré-escolas, foi construído um protocolo de avaliação (PROTOCOLO DE AVALIAÇÃO DO TRANSTORNO DO DESENVOLVIMENTO DA COORDENAÇÃO - TDC, 2009), que se encontra em fase de aprimoramento.

O protocolo foi baseado em referenciais teóricos que abordam os transtornos motores. A primeira parte é composta por 30 itens e consiste de um questionário destinado aos educadores e foi baseado nos artigos: Avaliação da Coordenação e Destreza Motora-ACOORDEM de Lívia C. Magalhães, Viviane C. S. Nascimento e Márcia B. Rezende (MAGALHÃES et al., 2004) e Enabling occupation through facilitating the diagnosis of Developmental Coordination Disorder de Cheryl Missiuna (MISSIUNA et al., 2006). O questionário foi formulado por perguntas de "sim" ou "não" referentes às atividades que as crianças realizam na escola, no lazer e em suas Atividades de Vida Diária (AVDs). No item referente à escola são abordadas questões relacionadas 
às habilidades motoras da criança que podem ser observadas no contexto escolar: escrever, pintar, recortar, realizar tarefas como brincar e participar das atividades recreativas. Outro aspecto abordado é a socialização da criança com seus pares, a forma de expressão e comunicação e sua organização dentro da sala de aula. No item relacionado ao lazer são abordadas as habilidades que a criança apresenta para brincar e participar de atividades motoras como, por exemplo, andar de skate, patins e jogar bola. Na etapa que questiona sobre as Atividades da Vida Diária (AVD's) o protocolo engloba as habilidades que a criança apresenta nos aspectos de higiene, alimentação e vestuário.

Quadro 1 - Critérios de avaliação dos Transtornos do Desenvolvimento da Coordenação segundo DSM - IV, CID-10 e os escores baixos das crianças na PEDI e na EPP-DP

\begin{tabular}{|c|c|c|}
\hline Critérios do PEDI & Critérios do EPP-DP & $\begin{array}{l}\text { Critérios do TDC segundo } \\
\text { DSM-IV e CID } 10\end{array}$ \\
\hline \multirow[t]{5}{*}{$\begin{array}{l}\text { Desempenho nas AVD's e na coordena- } \\
\text { ção motora de acordo com a avaliação } \\
\text { do cuidador. } \\
\text { Crianças selecionadas: com escore abaixo } \\
\text { de } 30 \text {. }\end{array}$} & $\begin{array}{l}\text { Desempenho e Participação nas seguintes } \\
\text { áreas: } \\
\text { - Locomoção } \\
\text { - Compreensão-cognição } \\
\text { - Interação Social } \\
\text { - Comunicação } \\
\text { - AVD'S } \\
\text { Crianças selecionadas: com escore menor } \\
\text { ou igual a } 4 \text {. }\end{array}$ & $\begin{array}{l}\text { Desempenho escolar: prejuízo motor fino } \\
\text { e cognitivo. } \\
\text { Dificuldade, lentidão, desinteresse por } \\
\text { atividades escolares (recortar, colorir, } \\
\text { escrever). }\end{array}$ \\
\hline & & $\begin{array}{l}\text { Baixo desempenho em AVD's que exigem } \\
\text { coordenação motora para o nível cognitivo } \\
\text { e idade cronológica. } \\
\text { Dificuldade, lentidão, desinteresse por } \\
\text { atividades diárias que demandam coorde- } \\
\text { nação motora (vestir, alimentar, abotoar } \\
\text { roupa, amarrar sapatos). }\end{array}$ \\
\hline & & $\begin{array}{l}\text { Desajeitamento ou incoordenação moto- } \\
\text { ra: derrubar objetos, cair, tropeçar. } \\
\text { Dificuldade em brincadeiras motoras como } \\
\text { jogar bola e andar de bicicleta. } \\
\text { Dificuldade em aprender atividades mo- } \\
\text { toras novas. } \\
\text { Cansa facilmente e possui pouco interesse } \\
\text { por atividades físicas. }\end{array}$ \\
\hline & & $\begin{array}{l}\text { Falhas no desenvolvimento motor: fala, } \\
\text { escrita e outras atividades e habilidades } \\
\text { corporais. } \\
\text { Parece ter que prestar mais atenção em } \\
\text { tarefas que exigem coordenação motora. }\end{array}$ \\
\hline & & Baixa auto-estima \\
\hline
\end{tabular}

Na segunda parte do protocolo de avaliação é averiguado o desempenho do desenvolvimento motor da criança a partir da aplicação de atividades e brincadeiras para crianças de três, quatro, cinco e seis anos. A seleção dos itens da avaliação foi fundamentada no Exame Neurológico Evolutivo, de Aron J. Diament (DIAMENT, 1982; MORETTI, PERTICARATI, S/D) e em uma revisão bibliográfica onde os autores Gesell e Amatruda (2000) e o inventário Portage Operacionalizado (WILLIAMS; AIELLO, 2001) foram utilizados como parâmetro para avaliação do desenvolvimento normal das crianças. Foram incluídos 10 itens que avaliam a fala, o equilíbrio estático e dinâmico, a coordenação apendicular, a coordenação tronco - membros, as sincinesias, o tônus muscular, os reflexos, a persistência motora e as funções cerebrais superiores (gnosias).

Construído o protocolo de avaliação, foi realizada uma aplicação piloto com quatro crianças com desenvolvimento típico que freqüentavam uma escola privada de ensino infantil e fundamental. Nesse piloto foi possível identificar o 
MAZER, E. P.; DELLA BARBA P. C. S. Identificação de sinais. Rev. Ter. Ocup. Univ. São Paulo, v. 21, n. 1, p. 74-82, jan./abr. 2010.

tempo gasto para a aplicação do teste, os materiais necessários e as principais dúvidas que poderiam aparecer no decorrer da aplicação. Foram selecionados materiais e brincadeiras para que a avaliação fosse aplicada de forma lúdica e dinâmica.

Quadro 2 - Descrição dos itens selecionados para a segunda parte da avaliação

\begin{tabular}{|l|}
\hline Fala: é observado nesse item se a criança consegue construir frases e assim, se comunicar verbalmente. \\
\hline Equilíbrio Estático: esse item avalia a habilidade que a criança apresenta em manter sua postura. \\
\hline Equilíbrio Dinâmico: esse item avalia a capacidade que a criança tem em manter seu corpo equilibrado enquanto se move. \\
\hline Coordenação Apendicular: esse item avalia as habilidades que a criança tem em movimentar seus membros ou manusear objetos com eles. \\
\hline $\begin{array}{l}\text { Coordenação tronco - membros: esse item avalia a associação que há entre o tronco e os membros inferiores da criança (para a idade de } 6 \text { anos } \\
\text { apenas). }\end{array}$ \\
\hline Sincinesias: esse item tem como propósito observar se a criança executa simetricamente seus movimentos. \\
\hline Tônus muscular: esse item tem como propósito observar o tônus muscular da criança, que é o estado parcial de contração de um músculo em repouso. \\
\hline Reflexos: esse item tem como propósito observar se a criança tem a habilidade de reagir automaticamente às estimulações. \\
\hline Persistência motora: esse item avalia a habilidade que a criança possui em manter o seu corpo em alguma atividade motora. \\
\hline Funções cerebrais superiores (gnosias): esse item avalia a capacidade que a criança tem de perceber e reconhecer os objetos e conceitos. \\
\hline
\end{tabular}

De quinze crianças selecionadas para participar do estudo, foi possível realizar a avaliação com dez, pois cinco não estavam freqüentando as creches e pré-escolas na época do estudo, por motivos de doença, mudança de cidade, entre outros. A pesquisadora compareceu a nove instituições de ensino do município para realizar a avaliação, mas efetivou a aplicação do protocolo com 10 crianças de seis instituições.

Quadro 3 - Número de crianças avaliadas por creche

\begin{tabular}{|c|c|}
\hline Creche /pré-escola & $\begin{array}{c}\text { Número de crianças avaliadas em cada } \\
\text { creche }\end{array}$ \\
\hline A & 0 \\
\hline B & 1 \\
\hline C & 2 \\
\hline D & 0 \\
\hline E & 4 \\
\hline F & 1 \\
\hline G & 1 \\
\hline H & 1 \\
\hline I & 0 \\
\hline Total $=9$ & Total $=10$ \\
\hline
\end{tabular}

\section{RESULTADOS}

OPROTOCOLODEAVALIAÇÃODOTRANSTORNO DO DESENVOLVIMENTO DA COORDENAÇÃO (TDC) - 2009 foi elaborado com a finalidade de detectar sinais de Transtorno do Desenvolvimento da Coordenação e foi aplicado em crianças de três a seis anos que freqüentavam creches e pré-escolas municipais de uma cidade do interior do estado de São Paulo. Os resultados são apresentados em duas partes, conforme foi aplicado o protocolo e em seguida são analisados em sua totalidade.

\section{Primeira parte: Questionário para os professores}

A Tabela 1 mostra a pontuação que cada criança atingiu em cada item, de acordo com o questionário aos educadores. O número ao lado esquerdo da barra é o número de acertos, o número ao lado direito da barra é o número de questões consideradas. É apresentada também a porcentagem de acertos que cada criança obteve em cada item.

Foi considerada a seguinte porcentagem de acertos em qualquer item para fins de avaliação do protocolo:

$0-50 \%$ : a criança necessita de intervenção;

$50-75 \%$ : é necessário observar a criança em seu cotidiano;

75 - 100\%: a criança apresenta desenvolvimento considerado típico.

\section{Segunda parte: Avaliação com a Criança}

Para a avaliação do desempenho das crianças, foram planejadas atividades interativas, em forma de um circuito, que envolviam as habilidades a serem pesquisadas. A avaliação foi realizada no ambiente das creches e préescolas.

As crianças JVG, MEB e VGF apresentaram dificuldades na primeira e segunda partes do protocolo, portanto, tem indicação para serem encaminhadas a uma avaliação detalhada do desenvolvimento. 
MAZER, E. P.; DELLA BARBA P. C. S. Identificação de sinais. Rev. Ter. Ocup. Univ. São Paulo, v. 21, n. 1, p. 74-82, jan./abr. 2010.

Tabela 1 - Pontuação das crianças na primeira parte do protocolo de avaliação: questionários aos educadores

\begin{tabular}{l|llllll}
\hline Crianças & $\begin{array}{l}\text { Idade } \\
\text { criança }\end{array}$ & Escola & AVD's & Lazer & $\begin{array}{l}\text { Incoordenação } \\
\text { Motora }\end{array}$ & Interpretação dos resultados \\
\hline 1. G.V.L & 3 anos & $9 / 12=75 \%$ & $7 / 8=87,5 \%$ & $5 / 7=71,4 \%$ & $5 / 5=100 \%$ & Observar \\
2. K.H.P & 3 anos & $7 / 12=58,3 \%$ & $6 / 8=75 \%$ & $7 / 7=100 \%$ & $5 / 5=100 \%$ & Observar \\
3. V.H.B & 3 anos & $9 / 12=75 \%$ & $8 / 8=100 \%$ & $5 / 7=71,4 \%$ & $5 / 5=100 \%$ & Observar \\
4. J.V.G & 4 anos & $3 / 10=30 \%$ & $6 / 8=75 \%$ & $1 / 6=16,6 \%$ & $1 / 5=20 \%$ & Intervenção \\
5. M.E.B & 3 anos & $2 / 11=18,2 \%$ & $6 / 8=75 \%$ & $4 / 7=57,2 \%$ & $1 / 5=20 \%$ & Intervenção \\
6.Ry.B.M & 3 anos & $8 / 11=72,8 \%$ & $8 / 8=100 \%$ & $6 / 7=85,7 \%$ & $5 / 5=100 \%$ & Observar \\
7. R.B.M & 3 anos & $10 / 11=90,9 \%$ & $8 / 8=100 \%$ & $6 / 7=85,7 \%$ & $5 / 5=100 \%$ & Desenvolvimento Típico \\
8. Y.C.F & 6 anos & $8 / 10=80 \%$ & $6 / 6=100 \%$ & $4 / 6=66,7 \%$ & $4 / 5=80 \%$ & Observar \\
9. V.G.F & 5 anos & $2 / 10=20 \%$ & $7 / 8=87,5 \%$ & $4 / 5=80 \%$ & $5 / 5=100 \%$ & Intervenção \\
\hline 10.B.V.S & 6 anos & $9 / 9=100 \%$ & $8 / 8=100 \%$ & $4 / 5=80 \%$ & $5 / 5=100 \%$ & Desenvolvimento Típico \\
\hline
\end{tabular}

Tabela 2 - Resultado da aplicação de atividades às crianças na segunda parte do protocolo de avaliação

\begin{tabular}{|c|c|c|c|c|c|c|c|c|c|c|c|}
\hline Crianças & $\begin{array}{l}1 . \\
\text { Fala }\end{array}$ & $\begin{array}{l}2 . \\
\text { Equi- } \\
\text { líbrio } \\
\text { Estático }\end{array}$ & $\begin{array}{l}3 . \\
\text { Equilíbrio } \\
\text { Dinâmico }\end{array}$ & $\begin{array}{l}4 . \\
\text { Coordenação } \\
\text { Apendicular }\end{array}$ & $\begin{array}{l}5 . \\
\text { Coordena- } \\
\text { ção Tronco } \\
\text { - Membros }\end{array}$ & $\begin{array}{l}6 . \\
\text { Sincine- } \\
\text { sias }\end{array}$ & $\begin{array}{l}7 . \\
\text { Tono } \\
\text { Mus- } \\
\text { cular }\end{array}$ & $\begin{array}{l}8 . \\
\text { Refle- } \\
\text { xos }\end{array}$ & $\begin{array}{l}9 . \\
\text { Persis- } \\
\text { tência } \\
\text { Motora }\end{array}$ & $\begin{array}{l}10 . \\
\text { Funções } \\
\text { cerebrais } \\
\text { (gnosias) }\end{array}$ & $\begin{array}{l}\text { Interpre- } \\
\text { tação dos } \\
\text { Resultados }\end{array}$ \\
\hline 1. G.V.L & & & & $\begin{array}{l}\text { Não construiu a } \\
\text { torre. } \\
\text { Não cortou com } \\
\text { tesoura. }\end{array}$ & & & & & & & \\
\hline 2. K.H.P & $\begin{array}{l}\text { Fala } \\
\text { pouco. }\end{array}$ & & $\begin{array}{l}\text { Apresentou } \\
\text { desequilí- } \\
\text { brio. } \\
\text { Não correu } \\
\text { contornando } \\
\text { obstáculos. }\end{array}$ & $\begin{array}{l}\text { Não conseguiu } \\
\text { chutar a bola. }\end{array}$ & & & & & & & \\
\hline 3. V.H.B & & & & $\begin{array}{l}\text { Não construiu a } \\
\text { torre. }\end{array}$ & & & & & & & \\
\hline 4. J.V.G & & & $\begin{array}{l}\text { Dificuldade } \\
\text { em andar } \\
\text { nas pontas } \\
\text { dos pés e em } \\
\text { pular para } \\
\text { frente e para } \\
\text { trás. }\end{array}$ & $\begin{array}{l}\text { Dificuldade em } \\
\text { cortar curvas } \\
\text { com a tesoura. }\end{array}$ & & & & $\begin{array}{l}\text { Re- } \\
\text { flexos } \\
\text { lentifi- } \\
\text { cados. }\end{array}$ & & $\begin{array}{l}\text { Não reconhe- } \\
\text { ceu posições } \\
\text { segmentares. } \\
\text { Não reconhe- } \\
\text { ceu as } \\
\text { cores preto e } \\
\text { branco. }\end{array}$ & Intervenção \\
\hline 5. M.E.B & Não fala. & & & & & & & & & & Intervenção \\
\hline 6. Ry.B.M & & & & $\begin{array}{l}\text { Não copiou } \\
\text { traço vertical. } \\
\text { Não jogou a } \\
\text { bola para o } \\
\text { examinador. } \\
\text { Não cortou com } \\
\text { tesoura. }\end{array}$ & & & & & & & \\
\hline 7. R.B.M & & & & $\begin{array}{l}\text { Dificuldades } \\
\text { em cortar com a } \\
\text { tesoura. }\end{array}$ & & & & & & & \\
\hline \multicolumn{12}{|l|}{ 8. Y.C.F } \\
\hline 9. V.G.F & & & & $\begin{array}{l}\text { Dificuldades } \\
\text { em abrir uma } \\
\text { mão e fechar a } \\
\text { outra. }\end{array}$ & & & & & & $\begin{array}{l}\text { Dificuldade } \\
\text { em manter } \\
\text { a língua } \\
\text { protusa com } \\
\text { os olhos } \\
\text { fechados. }\end{array}$ & Intervenção \\
\hline 10. B.V.S & & & & $\begin{array}{l}\text { Dificuldades } \\
\text { em andar en- } \\
\text { quanto enrolava } \\
\text { uma linha na } \\
\text { mão. }\end{array}$ & & & & & & & \\
\hline
\end{tabular}


A criança JVG apresentou, segundo o questionário aplicado com sua educadora, dificuldades nos itens da escola, lazer e incoordenação motora, e na avaliação motora, dificuldades nos aspectos de equilíbrio dinâmico, de coordenação apendicular bem como em reflexos e funções cerebrais. Resultado esse que pode ser indicativo de comprometimento relacionado ao Transtorno no Desenvolvimento da Coordenação, portanto, necessita de uma intervenção.

A criança MEB apresentou dificuldade na fala na segunda parte do protocolo, mas no relato da professora (parte 1), apresentou dificuldades nos itens da escola e da coordenação motora. Este resultado pode apontar que a dificuldade de verbalização pode interferir no desempenho de outros aspectos do desenvolvimento observados pela professora, mesmo que na avaliação direta $M$. tenha desempenhado as atividades de forma satisfatória. Considera-se, portanto, que M. necessita de intervenção pois a dificuldade em linguagem pode estar relacionada ao baixo desempenho em atividades do cotidiano da escola.

A criança VGF apresentou dificuldade em atividades relacionadas à escola (parte 1) e na avaliação (parte 2), V. apresentou dificuldade em coordenação apendicular e em funções cerebrais. Nesse caso, pode-se interpretar a necessidade de uma intervenção para estimular as dificuldades motoras que a criança apresenta e que podem estar interferindo em suas atividades escolares.

\section{DISCUSSÃO}

Identificou-se no presente estudo a importância de detectar os sinais do TDC principalmente na criança em fase pré-escolar, a fim de se programar intervenções que possam melhorar a qualidade de vida e minimizar as conseqüências do transtorno como: baixa auto-estima, dificuldade em envolver-se em brincadeiras com seus pares, dificuldades escolares tanto psicomotoras quanto emocionais que possam interferir no futuro desempenho escolar, entre outras.

A construção e validação de instrumentos de identificação do TDC tem sido um desafio para a área da Terapia Ocupacional. Em vista disso, esta pesquisa buscou apresentar os caminhos possíveis para se criar um instrumento que consiga compreender os sinais do Transtorno do Desenvolvimento da Coordenação e assim, nortear as possibilidades terapêuticas a partir de seus resultados. Pode-se dizer também que o presente estudo vem contribuir com a investigação e comunicação entre os pesquisadores dessa área, diante da insipiência de trabalhos voltados à identificação e intervenção do TDC no Brasil, embora tenha sido constatada na literatura a grande prevalência do transtorno em crianças de idade pré-escolar e escolar.

Adicionalmente, considera-se que a Terapia Ocupacional tem uma importante atuação junto às crianças com transtornos motores e seus familiares, pois pode lançar mão de estratégias de estimulação da criança, como integração sensorial, reorganização do cotidiano, treino de habilidades para a vida diária, adaptação de materiais, avaliação do ambiente e indicação de modificações de acordo com as necessidades de cada criança. A Terapia Ocupacional tem em seu rol de ações estratégias de orientação aos pais e educadores que podem minimizar as dificuldades das crianças que apresentam transtornos motores.

$\mathrm{O}$ instrumento elaborado para o presente estudo parece ter sido sensível para elencar aspectos importantes relacionados aos Transtornos do Desenvolvimento da Coordenação, pois de 10 crianças avaliadas, três foram identificadas com sinais relacionados ao TDC. Considerase que os sinais identificados são resultados preliminares da aplicação do referido protocolo, que está passando por uma revisão e seus itens estão sendo aprimorados como segunda etapa do projeto de pesquisa. Além das já indicadas, deverão ser observadas questões ambientais e contexto social das crianças avaliadas. Algumas perguntas aos educadores e itens da avaliação com as crianças também precisam ser reformuladas (por exemplo os relacionados à expressão verbal e desorganização motora e itens que avaliam a sincinesia e os reflexos). Finalmente, foi constatada a importância do terapeuta que aplica a avaliação ter conhecimento sobre o desenvolvimento infantil e os principais aspectos do TDC, para ter um melhor domínio sobre a avaliação e saber interpretar seus resultados.

\section{CONCLUSÕES}

Observou-se no presente estudo a necessidade de o Transtorno do Desenvolvimento da Coordenação ser estudado criteriosamente, não somente para uma melhor compreensão de seus aspectos, mas também pela prevalência em que é encontrado em crianças de idade pré-escolar. A partir de um norteamento a respeito desse transtorno, o trabalho dos profissionais pode enfocar a melhora da condição de vida desses indivíduos. Assim, destaca-se a necessidade de identificação e encaminhamento da criança que apresenta transtornos motores aos serviços de reabilitação, a fim de ajudá-las a superar suas dificuldades e potencializar suas habilidades. Partindo desse pressuposto, aponta-se como futuros objetivos dessa pesquisa o aprimoramento do protocolo desenvolvido, para que ele possa ser replicado em outros estudos. 
Coloca-se também como fundamental a atuação da Terapia Ocupacional com essas crianças, pela possibilidade do olhar para seu cotidiano e para a inserção nos diversos contextos que podem maximizar as potencialidades das crianças e orientar os cuidadores quanto ao manejo das dificuldades apresentadas pelo transtorno.

MAZER, E. P.; DELLA BARBA P. C. S. Identify signs of developmental coordination disorders in children aged three to six years with and possible performance of Occupational Therapy. Rev. Ter. Ocup. Univ. São Paulo, v. 21, n. 1, p. 74-82, jan./abr. 2010.

\begin{abstract}
The Developmental Coordination Disorder - DCD - has been studied as a delayed motor development, in which the motor difficulties may appear unrelated to neurological disorders or trauma. Manifests itself early, and children can have, even in preschool, delay in motor acquisition. Whatever the cause, prevention and detection of DCD require careful evaluation and use of specific tests to diagnose it. Objectives: To list the main features of Developmental Coordination Disorder and detect the signs have already been identified in children at risk for developmental delay in nurseries and preschools. Methodological procedure: it was developed and implemented a protocol for assessment of signs of the disorder for children aged between three to six years. Theoretical Approach: The protocol consists of two parts, the first in a questionnaire to educators and the second an assessment of child development. Results: The study included 10 children, three of them identified with signs of the disorder. The results indicate both the possibility of identifying the disorder, as to the need to refine the instrument so it can be replicated. Conclusions: The research emphasizes the possibilities of performance of occupational therapy in this population, the possibility of looking at your daily life and its insertion in the different contexts of the child.
\end{abstract}

KEY WORDS: Motor skills disorders. Developmental coordination Disorder. Occupational therapy. Protocols. Evaluation. Child, preschool. Activities of daily living.

\title{
REFERÊNCIAS
}

ASSOCIAÇÃO PSIQUIÁTRICA AMERICANA. DSM-IV: Manual diagnóstico e estatístico de transtornos mentais: DSMIV. Coord. Miguel Jorge. Tradução de Dayse Batista Porto Alegre: Artes Médicas, p. 49-50, 2002.

BRUININKS, R. H. Bruininks-Oseretsky Test of Motor Proficiency. Circle Pines, American Guidance Service, 1978.

DANTAS, L. E. B. T., MANOEL, E. J. Crianças com dificuldades motoras: questões para a conceituação do Transtorno do desenvolvimento da Coordenação. Rev. Movimento (ESEF, UFRGS), v. 15, n. 3, 2009. Disponível em: http://www.seer.ufrgs. br/index.php/Movimento/article/viewArticle/3908/5839. Acesso em 15 maio 2010.

DAVID, K. S. Developmental coordination disorder. In: CAMPBELL, S. Physical therapy for children. Philadelphia, WB Saunders, 1995.

DIAMENT, A. J. Índices clínicos no desenvolvimento neurológico da criança. Pediatria, São Paulo, p.345-356, 1982.

DELLA BARBA, P. C. S.; MAZER, E. P. Protocolo de Avaliação de Transtornos do Desenvolvimento da Coordenação. Relatório parcial do projeto de Iniciação Científica "Transtornos do Desenvolvimento da Coordenação em crianças: a prematuridade como fator de risco e as possibilidades de intervenção da Terapia Ocupacional", vinculado ao Programa Integrado de Apoio ao Docente Recém-Doutor - PIADRD/PROPQ/UFSCar, jan., 2010.

GESELL, A.; AMATRUDA. Diagnóstico do desenvolvimento: avaliação e tratamento do desenvolvimento neuropsicológico do lactente e da criança pequena, o normal e o patológico. 3a. ed. São Paulo: Atheneu, 2000.

GUBBAY, S. S. The clumsy child - a study of developmental apraxia and agnosic ataxia. Philadelphia: WB Saunder, 1975.

HENDERSON, S. E.; SUDGEN, D. A. Movement assessment batery for children. Sidcup: the Psychological Corporation, 1992.

LACERDA, T. T. B. Validade de conteúdo de questionários de coordenação motora para pais e professores. Rev. Ter. Ocup. Univ. São Paulo, v. 18, n. 2, p. 63-77, 2007.

LACERDA, T. T. B., MAGALHÃES, L. C.; REZENDE, M. B. Validade de conteúdo de questionários de coordenação motora para pais e professores. Rev. Ter. Ocup. Univ. São Paulo, v. 18, n. 2, p. 63-77, 2007.

MAGALHÃES, L. C. et al. Avaliação da coordenação. Rev. Ter. 
Ocup. Univ. São Paulo, v. 15, n. 1, p. 17-25, 2004.

MAGALHAES, L. C. Transtornos da coordenação motora e da aprendizagem. In: CAVALCANTI; GALVÃO (Org.) Terapia ocupacional: fundamentação \& prática. Rio de Janeiro: Guanabara Koogan, 2007. p.314-327.

MANCINI, M. Inventário de avaliação pediátrica e de incapacidade (PEDI): manual da versão brasileira adaptada. Belo Horizonte: 2005.

MARTINEZ, C. M. S.; PINHEIRO, R.. C.; ROSSI, L. M.; PINTO, B. T. Fatores de risco e proteção ao desenvolvimento saudável de crianças de 0 A 5 anos: contribuições da Terapia Ocupacional na geração de recursos e na orientação aos educadores de creche, relatório de pesquisa, 2007.

MARTINI, R. H.; POLATAJKO, H. J. Verbal self guidance as a treatment approach for children with developmental coordination disorder: a systematic replication study. Occup. Ther. J. Res., v. 18 , n. 4, p.157-81, 1998.

MISSIUNA, C.; et al. Enabling occupation through facilitating the diagnosis of Developmental Coordination Disorder. Rev. Canadienne D'Ergother., v. 75, n. 1, 2006.

MORETTI, A. L. C.; PERTICARATI, A. M. Adequação do exame neurológico evolutivo (ANE) para avaliação motora de crianças da faixa etária de 6 e 7 anos em atividades diárias no ambiente da creche. Disponível em : http://www.unimep.br/phpg/ mostraacademica/anais/4mostra/pdfs/418.pdf. Acesso em: $17 \mathrm{de}$ setembro de 2009.

OMS. ORGANIZAÇÃO MUNDIAL DE SAÚDE. Classificação dos transtornos mentais e de comportamento da CID-10: descrições clínicas e diretrizes diagnósticas. Porto Alegre: Artes Médicas, 1993.

OMS. ORGANIZAÇÃO MUNDIAL DE SAÚDE. World Health Organization (WHO). International Classification of Functioning, Disability and Health - Children and Youth Version. ICF-CY, WHO Press, 2007.

SELLERS, J. S. Clumsiness: review of causes, treatment, and outlook. Occup. Ther. J. Res., v. 15, n. 4, p. 39-55, 1995.

SOUZA, C.; FERREIRA, F.; CATUZZO, M. T.; CORRÊA, U. C. $\mathrm{O}$ teste $\mathrm{ABC}$ do movimento em crianças de ambientes diferentes. Rev. Portuguesa Ciên. Desporto, v. 7, n. 1, p. 36-47, 2007.

WILliams, LCA, AIEllo, ALR. Inventário Portage operacionalizado: intervenção com famílias. São Paulo: Memnon, 2001.

WRIGHT, H. C.; SUGDEN, D. S. The nature of development coordination disorder: inter - and intragroup differences. Adapted Phy. Activity Q., p.357-371, 1996. 